\title{
Probiotic fermented milk consumption modulates the allergic process induced by ovoalbumin in mice
}

\author{
Eva M. M. Velez ${ }^{1} \dagger$, Carolina Maldonado Galdeano ${ }^{1,2} \dagger$, Esteban Carmuega ${ }^{3}$, Ricardo Weill ${ }^{4}$, \\ María E. Bibas Bonet ${ }^{2}$ and Gabriela Perdigón ${ }^{1,2 *}$ \\ ${ }^{1}$ Centro de Referencia para Lactobacilos, CERELA-CONICET, Chacabuco 145, San Miguel de Tucumán-Tucumán, Argentina \\ ${ }^{2}$ Cátedra de Inmunología, Instituto de Microbiología, Facultad de Bioquímica, Química y Farmacia, UNT, Argentina \\ ${ }^{3}$ CESNI (Centro de Estudios Nutricionales Infantiles), Buenos Aires, Argentina \\ ${ }^{4}$ Director Cientifico Latam, DANONE Argentina S.A., Buenos Aires, Argentina
}

(Submitted 18 September 2014 - Final revision received 27 April 2015 - Accepted 11 May 2015 - First published online 16 July 2015)

\begin{abstract}
Orally administered probiotic micro-organisms are able to regulate the exacerbated immune response during the antigenic sensitisation process. The aim of the present study was to evaluate the potential efficacy of probiotic fermented milk (PFM) in preventing or treating allergy in an experimental model, and to investigate its underlying mechanisms. Ovoalbumin (OVA)-sensitised BALB/c mice were fed with PFM before the sensitisation procedure or fed continuously with PFM. At 7 and $15 \mathrm{~d}$ post-sensitisation, anti-OVA-specific IgE, IgG, IgG1 and IgG2a concentrations were measured in the serum and broncho-alveolar lavage fluid (BALF). Concentrations of interferon- $\gamma$ (IFN- $\gamma$ ), IL- 4 , IL-10 and total secretory IgA (S-IgA) were measured in the supernatants of macerated lungs or in the BALF. The levels of IgA ${ }^{+}, \mathrm{CD}^{+}{ }^{+}$and $\mathrm{CD}^{+} \mathrm{T}$ lymphocytes and $\mathrm{F} 4 / 80^{+}$cells were measured in the lungs by immunofluorescence. Inducible $\mathrm{CD} 4^{+} / \mathrm{CD} 25 / \mathrm{Foxp}^{+}$regulatory $\mathrm{T}$ $\left(\mathrm{T}_{\text {reg }}\right)$ cells were evaluated in the lungs. PFM shifted the T helper (Th)2 profile response towards a Th1 response that led to the production of IgG instead of IgE, with increasing levels of IL-10 and IFN- $\gamma$ that play an important role in immunomodulation exerted by PFM administration in sensitised mice. Anti-OVA-specific IgE levels were significantly decreased; however, there was no modification in the levels of anti-OVA-specific IgG and total S-IgA. PFM did not influence $T_{\text {reg }}$ cells in treated mice. Consumption of PFM could be a promising strategy in the amelioration of airway allergies, considering that the effect is mediated by the production of $\operatorname{IgG}$ through the activation of Th1 instead of the direct activation of Th2 cells to produce IgE.
\end{abstract}

Key words: Allergy model: Interferon- $\gamma$ : Ovoalbumin: Probiotic fermented milk: T helper 1/T helper 2 balance

In the past decades, respiratory allergic disorders increased dramatically, being the most common chronic diseases of childhood in developed countries. Hereditary predisposition and other factors related to the current lifestyle are responsible for different types of allergy.

The incidence of allergy has also been related to nutrition changes, the indiscriminate use of antibiotics, hygienic measures $^{(1)}$, and the number of births by caesarean section; all these points affect children during the first years of life, making them have less contact with a wide variety of microorganisms (hygiene hypothesis ${ }^{(2)}$ ) and inducing a complex process characterised by an excessive activation of $\mathrm{T}$ helper (Th2) cells against environmental antigens.
It has been established that the colonisation process of the intestinal microbiota early in life is essential to the development of the immune system ${ }^{(3)}$. Several studies have shown that the composition of the gut microbiota is different between healthy and allergic children ${ }^{(4,5)}$. This observation opens an important key in the study of intestinal microbiota and the ability to balance the populations of micro-organisms that exert beneficial features to the host; in this sense, probiotic bacteria are suitable candidates for improving the microbiota, especially when administered in foods without altering the normal feeding behaviour.

Probiotics are defined as live micro-organisms that when administered in adequate amounts confer a health benefit on the host ${ }^{(6)}$. The beneficial properties of probiotics have been

\footnotetext{
Abbreviations: $5 \mathrm{dPFM}$, 5d with probiotic fermented milk; a-OVA, anti-ovoalbumin; BC, basal control; BALF, broncho-alveolar lavage fluid; CTREAT, continuous treatment; dPR, days post-restimulus; dPS, days post-sensitisation; FITC, fluorescein isothiocyanate; IFN- $\gamma$, interferon- $\gamma$; LS, lung supernatant; NC, normal control; OVA, ovoalbumin; PTREAT, previous treatment; PFM, probiotic fermented milk; S-IgA, secretory IgA; SC, sensitisation control; Th, $\mathrm{T}$ helper; $\mathrm{T}_{\mathrm{reg}}$, regulatory $\mathrm{T}$.
}

*Corresponding author: Dr G. Perdigón, fax +54381 4310465, email perdigon@cerela.org.ar

† Both authors contributed equally to this work. 
reported under different conditions, such as protective effect against intestinal infections ${ }^{(7)}$, decrease in serum cholesterol ${ }^{(8,9)}$, modulating the immune system ${ }^{(10)}$ and reduction in the risk for the development of allergy ${ }^{(11)}$. Lactic acid bacteria, especially lactobacilli and bifidobacteria, are frequently used as probiotics, and studies conducted with these micro-organisms have shown that they are able to suppress allergic reactions in different animal models ${ }^{(12,13)}$ as well as in human subjects ${ }^{(14)}$. There have been many reports indicating that oral administration of probiotics has an effect on the reduction in IgE level in the serum of experimental allergic animals. In this sense, administration of Lactobacillus GG during the prenatal period reduced allergy symptoms in mouse models of allergic airway inflammation ${ }^{(15)}$.

The aim of the present study was to determine whether the oral administration of a probiotic fermented milk (PFM) regulates the immune response to IgE against ovoalbumin (OVA) in a mouse model of airway allergy (airway hypersensitivity), and to study the possible mechanisms involved in this effect by analysing regulatory $\mathrm{T}\left(\mathrm{T}_{\text {reg }}\right)$ cells and the modulation of specific IgG and total secretory IgA (S-IgA) antibody responses.

\section{Experimental methods}

\section{Experimental animals and probiotic fermented milk} administration

Male BALB/c mice ( $25 \pm 2 \mathrm{~g}$ ), aged 5 weeks old, were obtained from a closed-bred randomised colony, maintained at CERELA (Centro de Referencia para Lactobacilos, San Miguel de Tucumán, Argentina). Mice were kept in separate cages with a controlled atmosphere $\left(22 \pm 2{ }^{\circ} \mathrm{C}\right.$ and $55 \pm 2 \%$ relative humidity) and $\mathrm{a} 12 \mathrm{~h}$ light $-12 \mathrm{~h}$ dark cycle. They were fed with a conventional balanced diet ( $23 \%$ proteins, $6 \%$ raw fibre, $10 \%$ total minerals, $1.3 \% \mathrm{Ca}, 0 \cdot 8 \% \mathrm{P}, 12 \%$ moisture and vitamins) and water ad libitum throughout the experiment.

PFM used in the present study contained the yogurt starters Lactobacillus bulgaricus $\left(10^{8}\right.$ colony-forming units (CFU)/ml), Streptococcus thermophilus $\left(10^{8} \mathrm{CFU} / \mathrm{ml}\right)$ and the probiotic Lactobacillus paracasei ssp. paracasei CNCMI-1518 $\left(10^{8} \mathrm{CFU} / \mathrm{ml}\right.$ ) (former $L$. casei DN114001). Mice were fed ad libitum with PFM. Consumption of PFM was controlled ( $3 \mathrm{ml} /$ mouse). Mice received PFM $5 \mathrm{~d}$ before the sensitisation procedure, after which they were divided into two groups: mice that continued to receive the treatment until the end of the study (continuous treatment) and mice that received PFM only $5 \mathrm{~d}$ before OVA challenge (previous treatment) Control mice (without PFM treatment) were sensitised with OVA.

All animal protocols and trials were carried out in accordance with the current laws in Argentina, and were approved by the Ethical Committee of CERELA (protocol no. CRL-BIOT-LI-2011/1 ${ }^{\mathrm{a}}$ ).

\section{Sensitisation model}

In the present study, we selected an OVA sensitisation model because it is an appropriate antigen for studying antibody responses and allows comparison between specific IgE and IgG responses. Therefore, it is one of the most utilised antigens suitable for designing allergy models ${ }^{(16,17)}$.
The antigen was administered by three subcutaneous injections $(0.05 \mathrm{ml}, 0 \cdot 1 \%)$ diluted in PBS solution, separated by $1 \mathrm{~d}$. Thereafter, mice were exposed to OVA aerosols (1\% in PBS) for $20 \mathrm{~min}$ for 7 consecutive days.

Mice were divided into five experimental groups: (1) normal control (NC, standard diet + water); (2) basal control (BC, standard diet $+5 \mathrm{dPFM}$ ); (3) sensitisation control (SC, standard diet + OVA); (4) previous treatment (PTREAT, 5 dPFM + OVA + water); (5) continuous treatment (CTREAT, $5 \mathrm{dPFM}+$ OVA + PFM). Samples of serum, broncho-alveolar lavage fluid (BALF), lung tissue and macerated lungs were collected at 7 and $15 \mathrm{~d}$ after the last exposure to OVA (days post-sensitisation; dPS). After the last sample collection, mice from each experimental group were restimulated with the antigen as follows: at $15 \mathrm{dPS}$, mice received one injection of OVA $(0.05 \mathrm{ml}, 0 \cdot 1 \%)$, and then they were again exposed to OVA aerosols for 3 consecutive days and received one injection of OVA. The samples were collected $2 \mathrm{~d}$ post-restimulus (dPR). The body weight of mice was controlled weekly during the experiment. No differences were found in body weight between the treatment groups (data not shown).

$\mathrm{BALB} / \mathrm{c}$ mice are a suitable model for sensitisation with OVA, with responses similar to those found for human subjects. This animal model was chosen, as it does not cause severe respiratory outcomes.

\section{Determination of anti-ovoalbumin IgE, IgG, IgG1 and IgG2a, IL-4, IL-10 and interferon- $\gamma$ levels in serum by ELISA}

Before the collection of blood samples, mice were anaesthetised using a ketamine-xylazine mixture. Mice were bled at 7 and $15 \mathrm{dPS}$, and the blood sample was centrifuged at $800 \mathrm{rpm}$ for $10 \mathrm{~min}$. Serum was collected and stored at $-18^{\circ} \mathrm{C}$ until analysis. The levels of anti-OVA (a-OVA)-specific IgE and the cytokines IL-10, IL- 4 and IFN- $\gamma$ were measured in serum using commercially available ELISA kits (BD OptEIA $^{\mathrm{TM}}$ ), according to the manufacturer's instructions. Specific IgG, IgG1 and IgG2a antibody responses were determined by ELISA, according to the method described by Maldonado Galdeano et al. ${ }^{(18)}$ and Perdigón et al. ${ }^{(19)}$, respectively. For the detection of specific IgG, biotin SP-conjugated goat anti-mouse IgG (Jackson Immunoresearch Labs, Inc.) was used. For the detection of specific IgG1 or IgG2a, a rabbit anti-mouse antibody was used, respectively. The reaction was revealed with streptavidin-HRP (BD OptEIA ${ }^{\mathrm{TM}}$ ) and $3,3^{\prime}, 5,5^{\prime}$-tetramethylbenzidine reagent (BD Biosciences). For all cases, absorbance was read at $450 \mathrm{~nm}$. Cytokine levels are expressed as concentration $(\mathrm{pg} / \mathrm{ml})$, and the levels of specific antibodies are expressed as optical density.

Determination of anti-ovoalbumin IgE and $\lg G$, $I L-4, I L-10$, interferon- $\gamma$ and total secretory IgA levels in the broncho-alveolar lavage fluid and in the supernatants of macerated lungs by ELISA

Mice were killed by cervical dislocation at 7 and $15 \mathrm{dPS}$. Within the same experimental period, the lungs were 
washed with $1 \mathrm{ml}$ PBS $(0 \cdot 01 \mathrm{~m})$ by an intra-tracheal cannula and then the BALF was collected and stored at $-18^{\circ} \mathrm{C}$. Subsequently, one lobe of each lung used to collect the BALF was kept for immunofluorescence assays. The second lobe was used to prepare macerated lungs. Briefly, tissue was collected into $1.5 \mathrm{ml}$ of sterile PBS $(0.01 \mathrm{M})$ and disrupted using a homogeniser (MSE). The disrupted organs were centrifuged for $10 \mathrm{~min}$ at $1000 \mathrm{rpm}\left(4^{\circ} \mathrm{C}\right)$. Lung supernatants (LS) were collected and maintained at $-18^{\circ} \mathrm{C}$ until analysis. To measure the levels of specific IgE, IL-4, IL-10 and IFN- $\gamma$ from the BALF or LS, commercial ELISA kits (BD OptEIA ${ }^{\mathrm{TM}}$ ) were used according to the manufacturer's instructions. The level of specific IgG was also measured as described previously ${ }^{(18)}$. Total S-IgA level was measured according to the method described by de Moreno de LeBlanc et al. ${ }^{(20)}$, using goat anti-mouse IgA affinity-purified antibody (Bethyl Laboratories, Inc.). Kappa IgA-purified Ig (Sigma) was used as the standard. Detection was performed with anti-mouse IgA ( $\alpha$-chain-specific) peroxidase conjugated developed in goat (Sigma). All reactions were revealed and stopped as described previously. Absorbance was read at $450 \mathrm{~nm}$. Results for total S-IgA and cytokines are expressed as concentration $(\mu \mathrm{g} / \mathrm{ml}$ and $\mathrm{pg} / \mathrm{ml}$, respectively). Specific IgE and $\operatorname{IgG}$ levels are expressed as optical density at $450 \mathrm{~nm}$

\section{Determination of $\mathrm{IgA}^{+}, \mathrm{CD}^{+}, \mathrm{CD}^{+}$and $\mathrm{F} 4 / 80^{+}$cell} populations in the lungs by direct immunofluorescence assay

The number of IgA ${ }^{+}$cells was determined by direct immunofluorescence assay. After deparaffinisation of histological sections using xylene and rehydration in a decreasing gradient of ethanol, paraffin sections $(4 \mu \mathrm{m})$ were incubated with a dilution of $\alpha$-chain monospecific antibody conjugated with fluorescein isothiocyanate (FITC) (Sigma) for $30 \mathrm{~min}$ at $37^{\circ} \mathrm{C}$. To study the population of $\mathrm{CD}^{+} / \mathrm{CD}^{+}$cells, slides were incubated with FITC rat anti-mouse CD4 or CD8 (BD Pharmingen). Macrophages were determined using the FITC antimouse F4/80 antigen (eBioscience, Inc.). The cells were observed under a fluorescent light microscope at a magnification of $1000 \times$. The number of fluorescent cells was counted in thirty fields of vision. Results are expressed as the number of fluorescent cells per ten fields of vision.

\section{Determination of cytokine-positive cells in the lungs by indirect immunofluorescence assay}

Cytokine-positive cells were determined using indirect immunofluorescence assay. Paraffin sections were incubated with a blocking solution ( $1 \%$ bovine serum albumin; Sigma) for $30 \mathrm{~min}$ at room temperature. Slices were washed with PBS and incubated with normal goat serum (1:100) for $30 \mathrm{~min}$ at room temperature. Anti-murine IL- 4 , IL-10 and IFN- $\gamma$ (PeproTech, Inc.) were applied to tissue samples and incubated for $60 \mathrm{~min}$ at room temperature. Finally, the slices were washed two times with PBS and incubated with a goat anti-rabbit antibody conjugated with FITC (1:100; Jackson Immunoresearch
Labs, Inc.) for $45 \mathrm{~min}$ at room temperature, and washed twice in PBS.

The number of fluorescent cells was counted in thirty fields of vision at a magnification of 1000x. Results are expressed as the number of fluorescent cells per ten fields of vision.

\section{Determination of anti-ovoalbumin-specific $\lg E$ and $\lg C$ levels after $2 d$ post-restimulus}

Samples of blood and BALF were collected at $2 \mathrm{dPR}$ to measure the levels of a-OVA-specific $\operatorname{IgE}$ and $\operatorname{IgG}$ according to the techniques described previously.

\section{Histological staining with haematoxylin-eosin}

After deparaffinisation, histological sections from lung tissue were stained with haematoxylin-eosin for the analysis of cell infiltration in the lungs, focusing on granulocytes and inflammatory responses. A score was assigned according to Enander et $a l^{(21)}$ : $0=$ no cells around the blood vessels; $1=$ three cell layers around the blood vessels; $2=$ between four and ten cell layers around the blood vessels; $3=$ more than ten cell layers around the blood vessels. The study was performed qualitatively using light microscopy at a magnification of 1000x. Images are representative of each group.

\section{Determination of inducible $C D 4^{+} C D 25^{+}$Foxp $^{+}$ regulatory $T$ cells in the lungs by flow cytometry}

After sample collection, a portion of each lung was separated to determine the presence of $\mathrm{T}_{\text {reg }}$ cells. A free cell suspension $\left(1 \times 10^{6}\right.$ cells) was prepared mechanically and filtered using a $35 \mu \mathrm{m}$ nylon cell strainer (BD Falcon ${ }^{\mathrm{TM}}$ ) after lysing erythrocytes. Cells $\left(1 \times 10^{6}\right.$ cells $\left./ \mathrm{ml}\right)$ were incubated using a FITC rat anti-mouse CD4 and allophycocyanin (APC) rat antimouse CD25 (BD Pharmingen ${ }^{\mathrm{TM}}$ ). Then, the cells were prepared with stain buffer ( $2 \%$ PBS-fetal bovine serum) and mouse Foxp3 buffer set (BD Pharmingen ${ }^{\mathrm{TM}}$ ), according to the manufacturer's instructions, and incubated with $\mathrm{PE}$ rat anti-mouse Foxp3 antibody (BD Pharmingen ${ }^{\mathrm{TM}}$ ). The cells were detected using a BD FACSCalibur ${ }^{\circledR}$ (BD Biosciences). Data were analysed using FCS Express 4 Flow Research Edition software (De Novo Software), and are expressed as a percentage of $\mathrm{CD} 4^{+} / \mathrm{CD} 25^{+} / \mathrm{Foxp}^{+}$cells.

\section{Statistical analysis}

Each group and time assayed contained three mice. The sensitisation procedure with or without PFM treatment was carried out three times. Results are presented as means of three independent trials from nine mice with their standard errors of the mean. Statistical analysis was performed using MINITAB 15 software (Minitab, Inc.) by the ANOVA general linear model followed by Tukey's post hoc test. P0.05 was considered as significant. 


\section{Results}

Influence of probiotic fermented milk on anti-ovoalbuminspecific IgE, IgG and cytokine levels in serum

The results for specific IgE and IgG antibody responses at 7 and $15 \mathrm{dPS}$ showed that PFM was able to reduce the levels of a-OVA-specific IgE. At $7 \mathrm{dPS}$, mice that received PFM (PTREAT and CTREAT) had a significant decrease in the level of specific IgE compared with the SC group $(P \leq 0 \cdot 05)$. At $15 \mathrm{dPS}$, PFM also reduced the level of a-OVA-specific IgE only in mice that received the treatment until the end of the experiment (CTREAT) compared with the SC and PTREAT groups (Fig. 1(A)).

For a-OVA IgG, we found that all the sensitised groups exhibited an increase in the level of this antibody, being more significant in mice that received the CTREAT compared with the other groups (NC, BC, PTREAT and SC) at 7 and 15 dps ( $P \leq 0 \cdot 05$; Fig. $1(\mathrm{~B})$ ).

The analysis of the subclasses of IgG antibody showed that the level of IgG2a was predominant in the PTREAT and CTREAT groups compared with the IgG1 level. In particular, the IgG1 level was significantly reduced in the CTREAT group compared with the SC group at 7 and $15 \mathrm{dPS}$. In the treated groups, the IgG2a level significantly increased at $7 \mathrm{dPS}(P \leq 0 \cdot 05$; Fig. $1(\mathrm{C})$ and (D)).

Concerning IL-10, high levels were observed only at $7 \mathrm{dPS}$ in the serum of treated mice, being remarkable for those in the PTREAT group in comparison with the SC group
$(P \leq 0.05)$. At $15 \mathrm{dPS}$, the level of this cytokine decreased in the sensitised and treated groups (Fig. 2(A)).

Concerning IL-4, a slight increase in the level was observed with no significant difference between the serum of the SC group and the treated groups (Fig. 2(B)). IFN- $\gamma$ had no detectable levels (according to the ELISA kit sensibility) in the serum of all the treatment groups.

Study of the mucosal immune response in the lungs: release of antibodies and cytokines in the bronchoalveolar lavage fluid induced by probiotic fermented milk administration after antigen stimulation

In all the treatment groups, we analysed the production of specific IgE, IgG, total S-IgA, IL-4, IL-10 and IFN- $\gamma$ in the BALF and in the supernatants of the macerated lungs (LS). In the BALF, a significant peak was observed for a-OVAspecific IgE in the SC group at $7 \mathrm{dPS}$ compared with the PTREAT and CTREAT groups, which exhibited similar lower levels to those of the NC and $\mathrm{BC}$ groups. At $15 \mathrm{dPS}$, mice that received the PTREAT showed a higher level of this antibody (Fig. 3(A)). The level of a-OVA-specific IgG significantly increased in the BALF of mice receiving the PTREAT at $7 \mathrm{dPS}(P \leq 0.05)$; however, the levels of this antibody reduced significantly in both PTREAT and CTREAT groups at 15 dPS compared with the SC group (Fig. 3(B)). Specific $\operatorname{IgE}$ and IgG levels in the LS were below the detection level. For total S-IgA, PFM induced a higher production of this
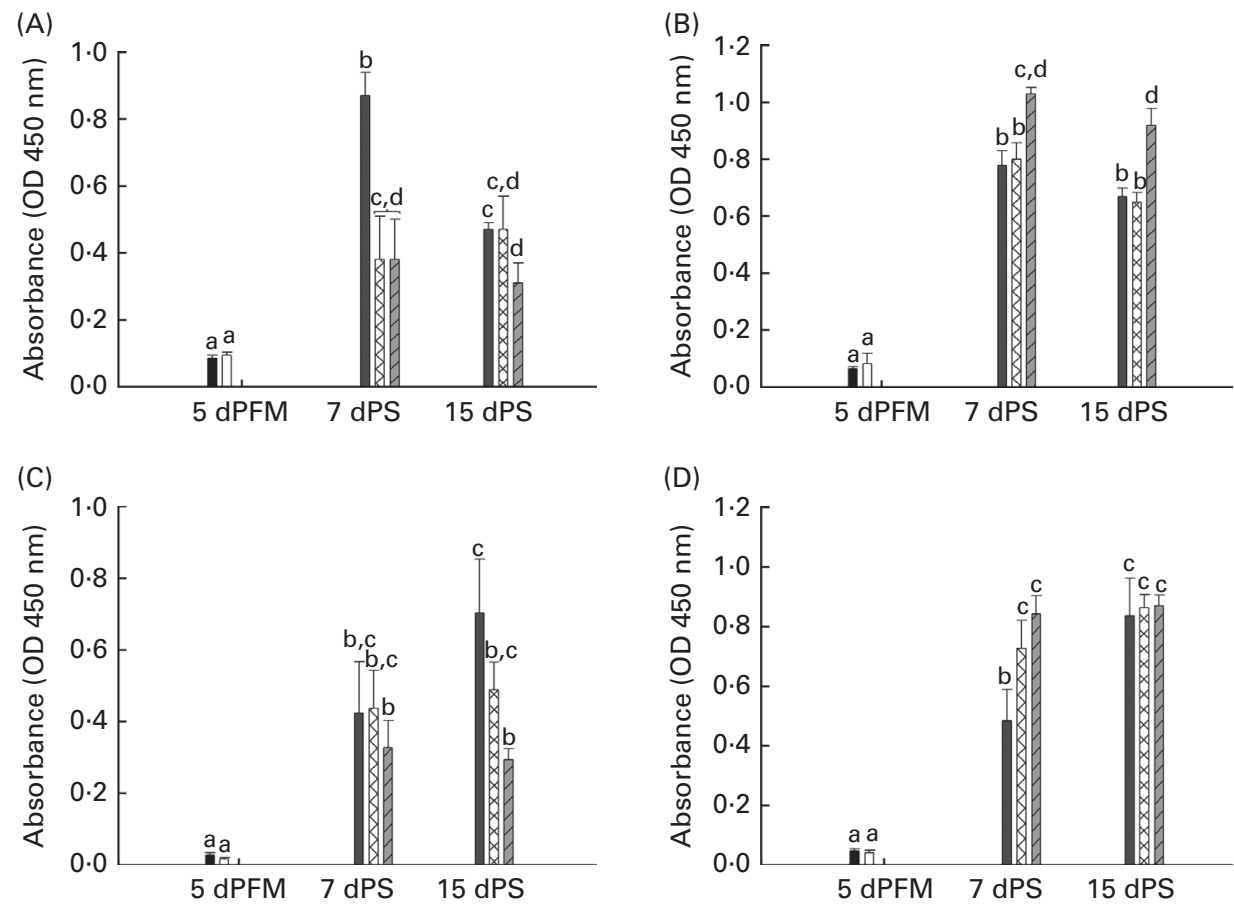

Fig. 1. Levels of (A) IgE, (B) IgG, (C) IgG1 (T helper (Th)2) and (D) IgG2a (Th1) in serum. Antibody responses were determined by ELISA in the serum of treated and non-treated mice (normal control $(\square)$, basal control ( $\square$ ), sensitisation control ( $\square$ ), previous treatment (PTREAT; 图) and continuous treatment (CTREAT; $\square$ )) at $5 \mathrm{~d}$ with probiotic fermented milk ( $5 \mathrm{dPFM}$ ) and at 7 and $15 \mathrm{~d}$ post-sensitisation (dPS). Results are expressed as the absorbance level (optical density (OD) at $450 \mathrm{~nm}$ ). Values are means ( $\mathrm{9}$ mice), with their standard errors represented by vertical bars. ${ }^{\text {a,b,c,d }}$ Mean values with unlike letters were significantly different $(P \leq 0.05)$. 

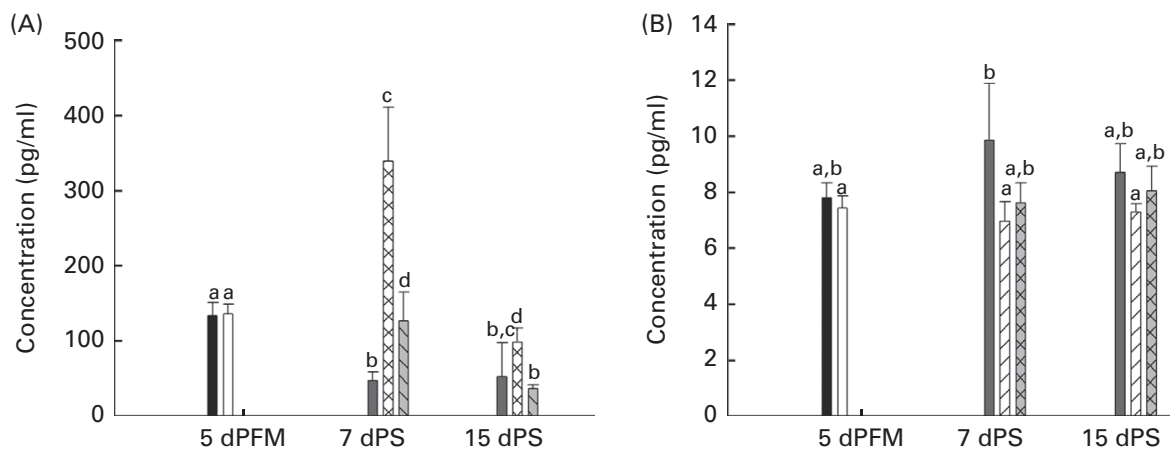

Fig. 2. Cytokine levels in the systemic immune response. (A) IL-10 and (B) IL-4 levels were analysed by ELSA in the serum of treated and non-treated mice

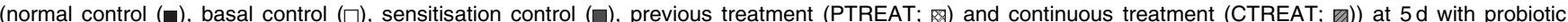
fermented milk ( $5 \mathrm{dPFM}$ ) and at 7 and $15 \mathrm{~d}$ post-sensitisation (dPS). Results are expressed as concentration (pg/ml). Values are means of three different trials ( $n 9$ mice), with their standard errors represented by vertical bars. ${ }^{a, b, c, d}$ Mean values with unlike letters were significantly different $(P \leq 0 \cdot 05)$.

antibody in the CTREAT group at $7 \mathrm{dPS}(P \leq 0 \cdot 05)$. At $15 \mathrm{dPS}$, all the sensitised groups presented similar levels of total S-IgA (Fig. 3(C)).

Cytokine analysis for IL-4 showed no statistical differences between the groups (NC, BC, SC, PTREAT and CTREAT) across the study periods ( $5 \mathrm{dPFM}, 7 \mathrm{dPS}$ or $15 \mathrm{dPS}$ ) (Fig. 4(A)). For IFN- $\gamma$, the CTREAT group showed a higher level of this cytokine in the LS at both 7 and $15 \mathrm{dPS}$, compared with the control and sensitised groups $(P \leq 0 \cdot 05$; Fig. $4(\mathrm{~B}))$. For IL-10, a significant peak was observed in the CTREAT group at $7 \mathrm{dPS}$ compared with the SC and PTREAT groups. However, in the CTREAT group, the level of IL-10 decreased at $15 \mathrm{dPS}$. In contrast, the SC group exhibited an increased level of IL-10 at $15 \mathrm{dPS}(P \leq 0 \cdot 05$; Fig. $4(\mathrm{C})$ ).

\section{Influence of probiotic fermented milk on the expression of} $\lg A^{+}$cells and $C D 4^{+}$lymphocytes but not on the expression of $\mathrm{CD}^{+}$or $\mathrm{F} 4 / 80^{+}$cells in the lungs

In the lungs, the expression levels of $\mathrm{IgA}^{+} \mathrm{B}$ lymphocytes were increased in mice that received the probiotic treatment until the end of the experiment (CTREAT group, 7 and $15 \mathrm{dPS})$ compared with the SC and NC groups $(P \leq 0.05$; Fig. 5(A)). The expression levels of $\mathrm{CD}^{+}{ }^{+} \mathrm{T}$ lymphocytes were significantly increased in the three sensitised groups in both study periods in comparison with the NC group
( $P \leq 0.05$ ), with the levels being higher in the SC group (Fig. 5(B)). OVA-sensitised mice with or without the probiotic treatment did not show significant differences in the number of cells expressing the CD8 marker in all the experimental groups (Fig. 5(C)). Similarly, no significant differences were found between the experimental groups and across the study periods in relation to macrophages that were counted by detecting the F4/80 marker (Fig. 5(D)).

\section{Influence of probiotic fermented milk on cytokine-secreting cells in lung tissue}

PFM influenced the expression of IL- 4 and IL-10 in different ways. For IL-10, the number of cells slightly increased in mice receiving the CTREAT and PTREAT compared with the SC, BC and NC groups at $15 \mathrm{dPS}(P \leq 0 \cdot 05)$. The number of $\mathrm{IL}-4^{+}$cells was significantly increased in the SC group, and the PTREAT and CTREAT groups maintained similar levels to those of the $\mathrm{NC}$ and $\mathrm{BC}$ groups ( $P \leq 0 \cdot 05$; Fig. 6(A) and (B) respectively).

\section{Effect of probiotic fermented milk in sensitised and restimulated mice}

To analyse the effect of PFM after re-exposure to the antigen at $2 \mathrm{dPR}$, a-OVA-specific IgE and IgG levels were measured in serum and BALF by ELISA $(P \leq 0 \cdot 05$; Table 1$)$. At $2 \mathrm{dPR}$, we
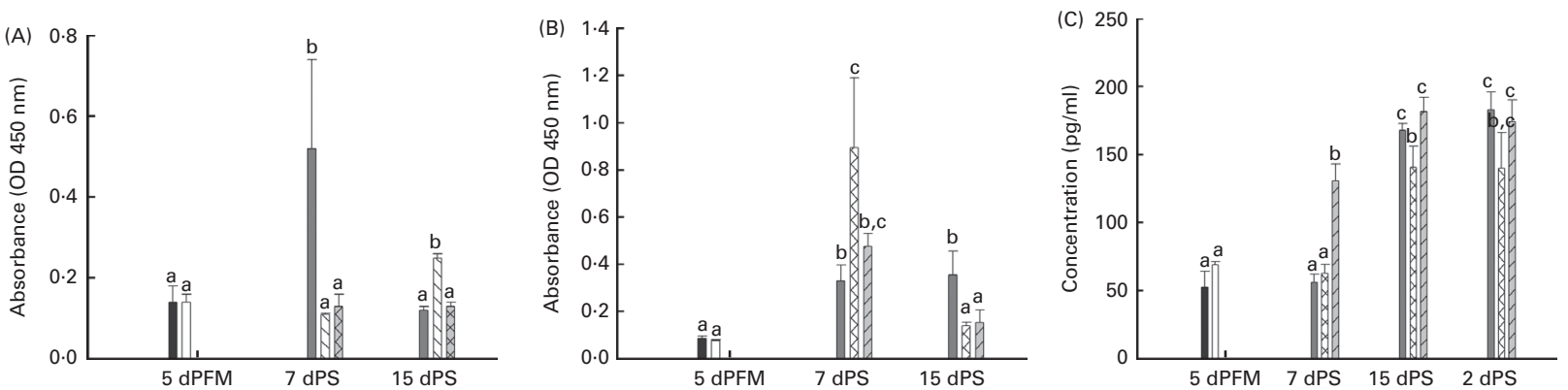

Fig. 3. Mucosal antibody immune responses in the broncho-alveolar lavage fluid (BALF). (A) Anti-ovoalbumin (a-OVA)-specific IgE, (B) a-OVA-specific IgG and (C) total secretory IgA (S-IgA) were determined by ELISA in the BALF of treated and non-treated mice (normal control $(\square)$, basal control $(\square)$, sensitisation control $(\square)$, previous treatment (PTREAT; 四) and continuous treatment (CTREAT; 四)) at $5 \mathrm{~d}$ with probiotic fermented milk (5 dPFM) and at 7 and $15 \mathrm{~d}$ post-sensitisation (dPS). Results for specific IgE and IgG are expressed as the absorbance level (optical density (OD) at $450 \mathrm{~nm}$ ), and those for total S-IgA are expressed as concentration $(\mu \mathrm{g} / \mathrm{ml})$. Values are means of three different trials $\left(n 9\right.$ mice), with their standard errors represented by vertical bars. ${ }^{\text {a,b,c,d }}$ Mean values with unlike letters were significantly different $(P \leq 0.05)$. 

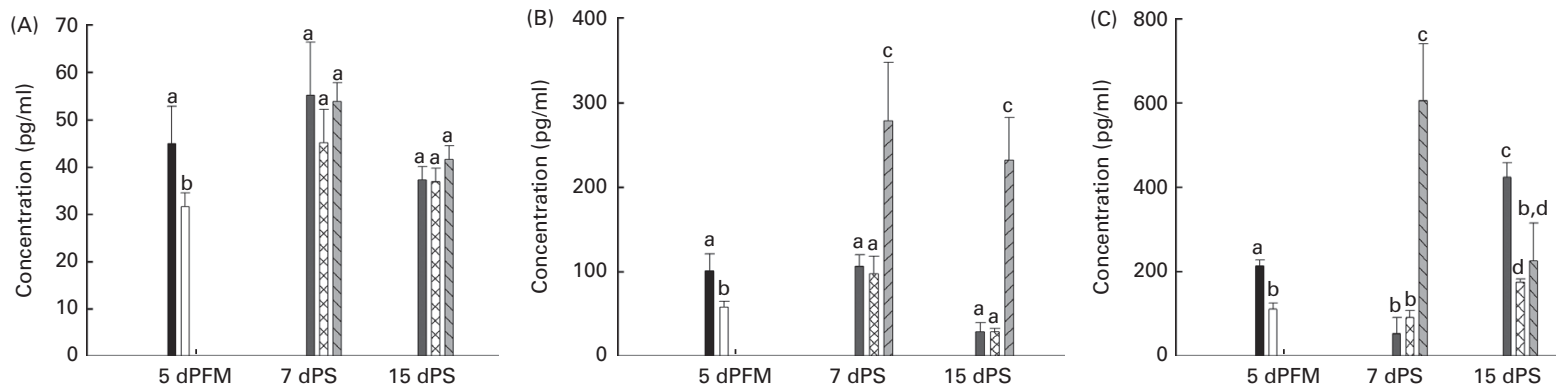

Fig. 4. Mucosal cytokine immune responses in the lungs. (A) IL-4, (B) interferon- $\gamma$ and (C) IL-10 levels were measured by ELISA in the supernatants of the macerated lungs of treated and non-treated mice (normal control $(\square)$, basal control $(\square)$, sensitisation control $(\square)$, previous treatment (PTREAT; 四) and continuous treatment (CTREAT; 四)) at $5 \mathrm{~d}$ with probiotic fermented milk ( $5 \mathrm{dPFM}$ ) and at 7 and $15 \mathrm{~d}$ post-sensitisation (dPS). Results are expressed as concentration (pg/ml). Values are means of three different trials ( $n 9$ mice), with their standard errors represented by vertical bars. ${ }^{a, b, c, d}$ Mean values with unlike letters were significantly different $(P \leq 0.05)$.

found that the level of a-OVA-specific IgE was decreased in the serum and BALF of mice receiving only the PTREAT. For a-OVA-specific IgG, PFM induced a significant increase in the level of this antibody in the serum and BALF of mice that received a CTREAT with PFM $(P \leq 0 \cdot 05$; Table 1$)$.

\section{$\mathrm{CD} 4^{+} \mathrm{CD} 25^{+} \mathrm{Foxp}^{+}$regulatory $\mathrm{T}$ cells}

The analysis of the presence of inducible $\mathrm{T}_{\text {reg }}$ cells in the lungs showed that mice sensitised with OVA had a reduced percentage of $\mathrm{CD}^{+} / \mathrm{CD} 25^{+} / \mathrm{Foxp}^{+}$cells in comparison with the $\mathrm{NC}$ group. However, the percentage of $\mathrm{T}_{\text {reg }}$ cells increased in the
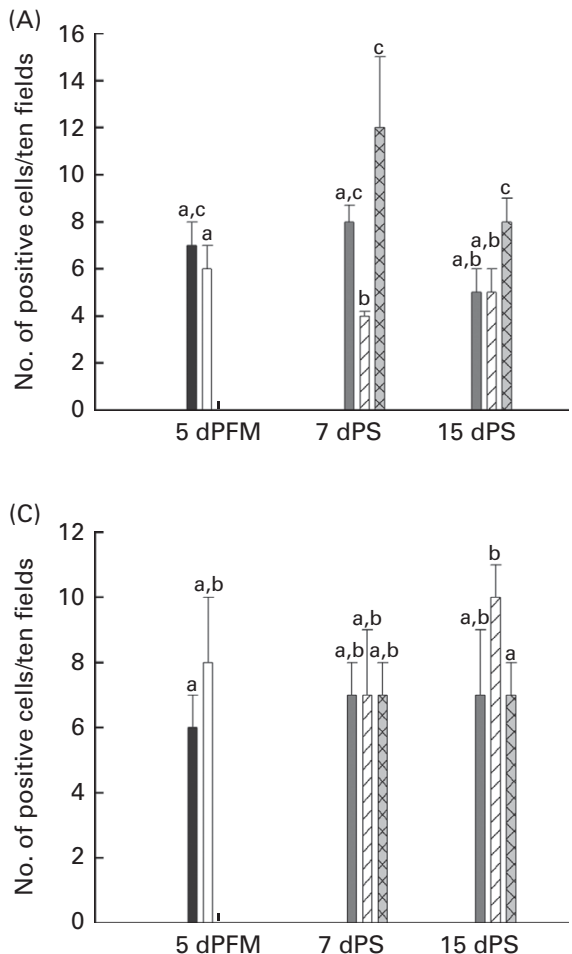

PTREAT and CTREAT groups at $15 \mathrm{dPS}$ compared with the SC group with no significant difference between the groups (Fig. 6(C)).

\section{Histological analysis of lung tissue}

Samples from the lungs stained with $\mathrm{H}-\mathrm{E}$ are shown in Fig. 7. Both the NC group (Fig. 7(A)) and the BC group (Fig. 7(B)) had a score of 0 . At $7 \mathrm{dPS}$, the SC group had score 1 (Fig. 7(C)), the PTREAT group had score 0 (Fig. 7(E)) and the CTREAT group had score 1 (Fig. $7(\mathrm{G})$ ). At $15 \mathrm{dPS}$, the SC group had score 2 (Fig. 7(D)), the PTREAT group had score 1
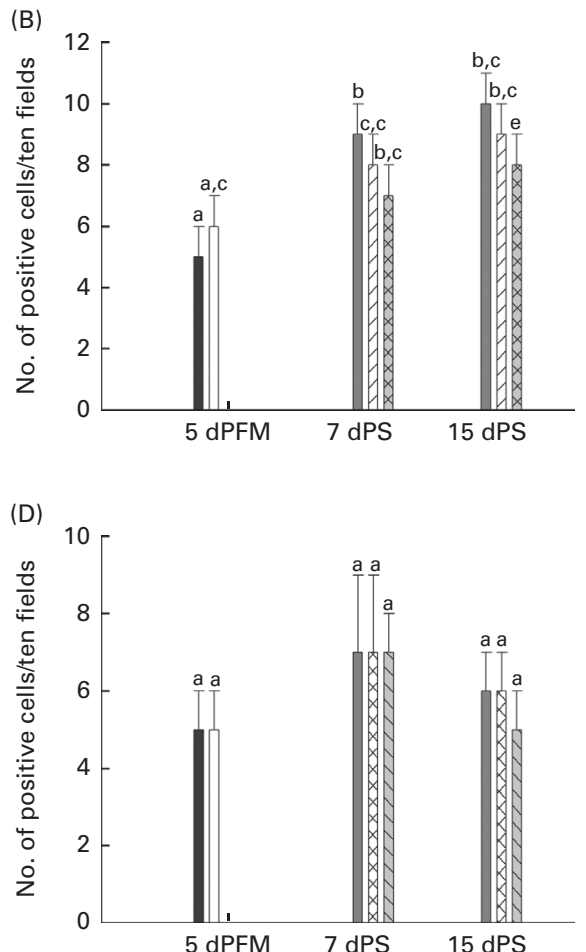

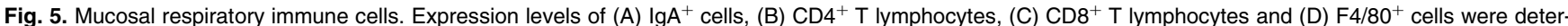
mined by direct immunofluorescence in the lung tissue of treated and non-treated mice (normal control ( $\square$ ), basal control ( $\square$ ), sensitisation control ( $\square$ ), previous treatment (PTREAT; ) and continuous treatment (CTREAT; $\mathbb{Z}$ )) at $5 \mathrm{~d}$ with probiotic fermented milk (5 dPFM) and at 7 and $15 \mathrm{~d}$ post-sensitisation (dPS). Positive cells were counted in tissue sections using a fluorescence microscope at a magnification of 1000x. The number of fluorescent cells was counted in thirty fields of vision. Results are expressed as the number of fluorescent cells per ten fields of vision. Values are means of three different trials ( $n 9$ mice), with their standard errors represented by vertical bars. ${ }^{\mathrm{a}, \mathrm{b}, \mathrm{c}, \mathrm{d}}$ Mean values with unlike letters were significantly different $(P \leq 0 \cdot 05)$. 
(A)

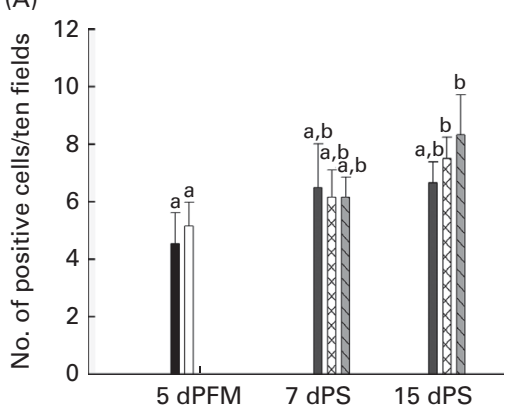

(B)

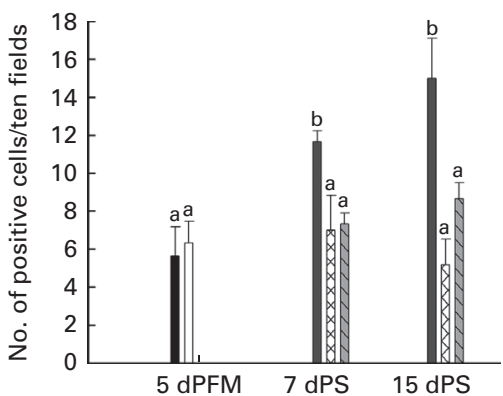

(C)

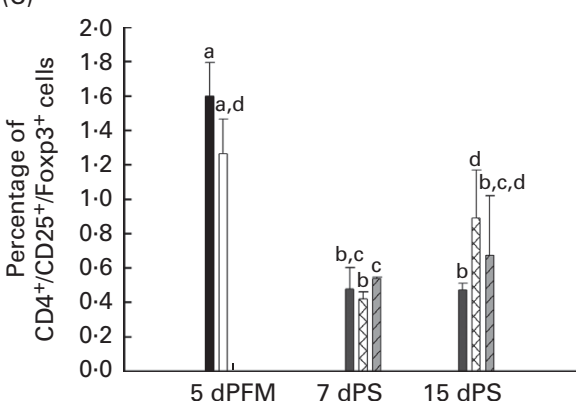

Fig. 6. Cytokine-producing cells and regulatory $T\left(T_{\text {reg }}\right)$ expression in the lungs. Expression levels of $(A) I L-10-$ and $(B)$ IL-4-producing cells were determined by indirect immunofluorescence in treated and non-treated mice (normal control ( $\square$ ), basal control ( $\square$ ), sensitisation control ( $\square$ ), previous treatment (PTREAT; ) and continuous treatment (CTREAT; $⿴ 囗 ⿱ 一 一))$ at $5 \mathrm{~d}$ with probiotic fermented milk ( $5 \mathrm{dPFM}$ ) and at 7 and $15 \mathrm{~d}$ post-sensitisation (dPS). Positive cells were counted in tissue sections using a fluorescence microscope at a magnification of 1000x. The number of fluorescent cells was counted in thirty fields of vision at a magnification of $1000 \times$. Results are expressed as the number of fluorescent cells per ten fields of vision. (C) Expression of $\mathrm{T}_{\text {reg }}$ cells was evaluated by the detection of $\mathrm{CD} 4^{+} /-$ $\mathrm{CD}^{2} 5^{+} / \mathrm{Foxp}^{+}$cells by flow cytometry. Results are expressed as a percentage of triple positive cells relative to the total number of CD $4^{+}$cells $(10 \%$ of the total suspension; data not shown). Values are means of three different trials ( $n 9$ mice), with their standard errors represented by vertical bars. ${ }^{\text {a,b,c,d }}$ Mean values with unlike letters were significantly different $(P \leq 0.05)$.

(Fig. 7(F)) and the CTREAT group had score 0 (Fig. 7(H)). We observed that mice receiving a CTREAT with PFM at 7 and $15 \mathrm{dPS}$ (Fig. $7(\mathrm{G})$ and $(\mathrm{H})$, respectively) showed a high frequency of mast cells (indicated by black arrows) and other granulocytic cells (indicated by white arrows); however, the structure of the tissue was conserved similar to that of the NC and BC groups. In contrast, for the SC group at 7 and $15 \mathrm{dPS}$ (Fig. 7(C) and (D), respectively) and for the PTREAT group at $15 \mathrm{dPS}$ (Fig. $7(\mathrm{~F})$ ), there was a higher cell infiltration with an increase in cell layers around the blood vessels, inducing a reduction in the alveolar space.

\section{Discussion}

Probiotic studies have demonstrated that these micro-organisms may favour immune responses in different pathologies such as allergic processes ${ }^{(22-25)}$. These studies have reported that oral administration of probiotics reduced the production of specific IgE in the serum of mice ${ }^{(13)}$, suggesting that the consumption of food products containing probiotic microorganisms may have a positive effect on the regulation of the immune system in the lungs.

Previous studies from our laboratory have demonstrated that oral administration of probiotics or fermented milk containing such micro-organisms induces the activation of the innate immune response to the gut level, with this beneficial effect also being observed in other distant mucosal sites such as lungs ${ }^{(10)}$. These previous studies have reported on the effect of PFM consumption for a prolonged period of time (14 weeks) on the cytokine profile of the adult host. In relation to IFN- $\gamma$, IL- 4 and IL-10 (investigated in the present study), we demonstrated that the levels of IFN- $\gamma$ and IL- 4 increased at the beginning of PFM administration (until 1 week), and then the levels of these cytokine-producing cells were maintained, with a slight increase being modulated by IL-10 throughout the experimental period (14 weeks) ${ }^{(26)}$.

In the present study, OVA-sensitised mice were used to evaluate the effect of PFM administration to attenuate the exacerbated Th2 immune response to $\operatorname{IgE}$ induced in the airways. We demonstrated that PFM decreases the levels of a-Ova-specific IgE. We analysed whether the reduction in the level of IgE influenced the level of specific IgG for the same T-dependent antigen. Total S-IgA production and the most relevant cytokines involved in the allergic process were studied in order to elucidate the possible mechanisms involved in the decrease of specific IgE levels.

Interestingly, clinical studies have shown that the beneficial effect of probiotic treatment occurs in the absence of IgE reduction $^{(27,28)}$. In contrast, Ohno et al. ${ }^{(13)}$ showed that oral administration of Bifidobacterium bifidum G9-1 to mice reduced the levels of total and allergen-specific IgE in serum, but had no effect on allergen-specific IgG1 or IgG2a levels.

In contrast to these findings, we observed that in our sensitisation model, the main effect exerted by the administration of PFM was the significant reduction in the specific IgE level in

Table 1. Influence of probiotic fermented milk on the levels of specific $\lg \mathrm{E}$ and $\operatorname{lgG} 2 \mathrm{~d}$ after a restimulus with ovoalbumin ( $2 \mathrm{~d}$ post-restimulus) measured in serum and broncho-alveolar lavage fluid (BALF)*

(Mean values with their standard errors from three different trials; $n 9$ mice)

\begin{tabular}{|c|c|c|c|c|c|}
\hline \multirow[b]{2}{*}{ Antibody } & \multirow[b]{2}{*}{ Experimental group } & \multicolumn{2}{|c|}{ Serum } & \multicolumn{2}{|c|}{ BALF } \\
\hline & & Mean & SEM & Mean & SEM \\
\hline \multirow[t]{3}{*}{ Specific IgE } & SC & $0.44^{a}$ & 0.11 & $0.38^{a}$ & 0.07 \\
\hline & $\mathrm{P}$ & $0.30^{a}$ & 0.03 & $0.19^{b}$ & 0.04 \\
\hline & C & $0.44^{\mathrm{a}}$ & 0.06 & $0.30^{\mathrm{a}}$ & 0.03 \\
\hline \multirow[t]{3}{*}{ Specific IgG } & SC & $0 \cdot 71^{a}$ & 0.02 & $0.67^{a}$ & 0.03 \\
\hline & $\mathrm{P}$ & $0.72^{a, b}$ & 0.10 & $0.92^{b}$ & 0.06 \\
\hline & $\mathrm{C}$ & $0.87^{\mathrm{b}}$ & 0.09 & $1 \cdot 11^{\mathrm{c}}$ & 0.06 \\
\hline
\end{tabular}

SC, sensitisation control; PTREAT, previous treatment; CTREAT, continuous treatment.

a,b,c,d Mean values with unlike superscript letters were significantly different $(P \leq 0.05)$.

* Specific IgE and IgG antibody responses were measured in the serum and BALF of the SC, PTREAT and CTREAT groups. Samples were collected $2 \mathrm{~d}$ after a short restimulation with ovoalbumin performed after the last sample collection ( $15 \mathrm{~d}$ post-sensitisation). Results are expressed as the absorbance level (optical density at $450 \mathrm{~nm})$. 


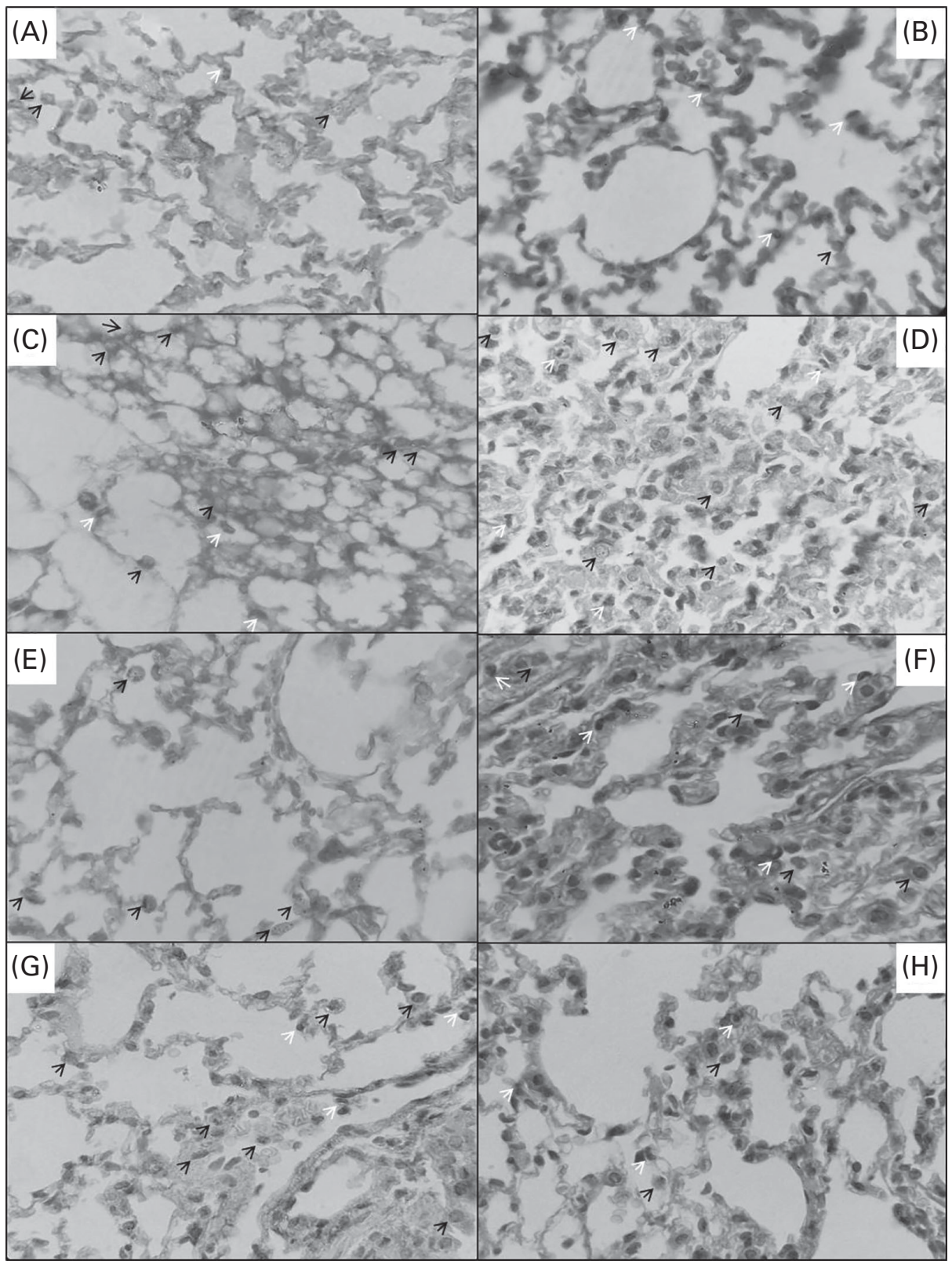

Fig. 7. Histological analysis of lung tissue. Histological analysis was performed by using the Enander score ${ }^{(19)}$, where lung tissue was classified from score 0 to 3 as follows: $0=$ no cells around the blood vessels; $1=$ one to three cell layers around the blood vessels; $2=$ four to ten cell layers around the blood vessels; $3=$ more than ten cell layers around the blood vessels. The analysis was performed qualitatively using light microscopy at a magnification of $1000 \times$. Images are representative of each treated and non-treated group of mice: (A) normal control; (B) basal control; (C, D) sensitisation control at 7 and $15 \mathrm{~d}$ post-sensitisation (dPS), respectively; (E, F) previous treatment at 7 and $15 \mathrm{dPS}$, respectively; $(\mathrm{G}, \mathrm{H})$ continuous treatment at 7 and $15 \mathrm{dPS}$, respectively. Black arrows, mast cells; white arrows, other granulocytic cells.

the serum and BALF of the PTREAT and CTREAT groups at 7 and $15 \mathrm{dPS}$, but not for the specific IgG level (Fig. 1(B)), shifting the Th1/Th2 balance towards a Th1 response, as demonstrated by the increase in the specific IgG2a level (Fig. 1(D)). However, after the restimulation of the antigen (2 dPR), PFM administration maintained the IgE and IgG values near to those of the SC group (Table 1).

The analysis of the balance between the IL- 10 and IL- 4 levels showed high levels of IL-10 and normal levels of IL- 4 in the serum of treated mice at $7 \mathrm{dPS}$ (Fig. 2(A) and (B)). However, the effect of PFM on the decreased synthesis of IgE had no effect on the production of specific IgG, which could be mediated by the regulation of B-cell clones to produce IgG instead of IgE through the activation of Th1. This speculation is supported by the fact that PFM mainly activates the innate immune response in the gut ${ }^{(29)}$, with an increased number of cytokine-producing cells (Th1/Th2 populations), as observed in previous work ${ }^{(26)}$, and influences the systemic immune response against OVA antigen ${ }^{(18)}$.

Previous results led us to analyse the cytokine profile in the lung. In post-sensitised mice, we determined that PFM did not have an effect on IL-4 production, but induced high levels of 
both IL-10 (7 dPS) and IFN- $\gamma$ (7 and $15 \mathrm{dPS}$ ) (Fig. 4(B) and (C)). The latter cytokine is important in the regulation of IL-4 $4^{(30)}$.

It is well known that IL-10 exerts a regulatory effect during inflammation in the mucosa. This could be attributed to the reduction in the level of specific IgE in serum and BALF for $7 \mathrm{~d}$ after the last antigen exposure. The high levels of IFN- $\gamma$ could regulate the immune response at $7 \mathrm{dPS}$ and control the production of IL-10 at $15 \mathrm{dPS}$, as observed in the present study (Fig. 4)

Recently, new anti-inflammatory/regulatory functions of IFN- $\gamma$ have been studied. One of its functions is the ability to inhibit the production of IL-17 and promote the maturation of B-lymphocytes and the production of $\operatorname{IgG} 2 \mathrm{a}^{(31)}$. These observations are consistent with the present results, and could be correlated with the high levels of IFN- $\gamma$ induced by PFM and specific IgG2a found in the serum of the CTREAT group, favouring the Th1 balance.

This finding led us to explore another hypothesis to explain the origin of IL-10 that is different from $\mathrm{T}_{\text {reg }}$ (absent in the three sensitised groups) or Th2 cells. The latter cell population (Th2) was excluded, considering that the IL-4 level was not increased in the treated groups, but only in the SC group. Therefore, we reinforce the balance towards a Th1 response correlated with the high levels of IFN- $\gamma$ released in the lungs and the balance towards IgG2a associated with antibody production. Although Th2 is the key cell to induce the production of antibody against T-dependent antigens such as OVA, Th1 cells are able to initiate immune responses against vaccine antigens such as toxoids (diftericum or tetanicum) with the release of IL-2. We demonstrated that L. casei CRL 431 and the PFM used in the present study increase the release of IL-2 ${ }^{(26,32)}$. There are new findings demonstrating that Th1, macrophages and even mast cells can release IL-10. We believe that IL-10 could be released from the Th1 cell population, more than from Th2 cells, which is in agreement with the results reported by O'Garra \& Vieira ${ }^{(33)}$ and Maldonado Galdeano et al. $^{(34)}$.

The results found for $\mathrm{TCD}^{+}, \mathrm{TCD}^{+}$and $\mathrm{F} 4 / 80^{+}$cells demonstrated that PFM consumption has an impact only on the profile of cytokine production; however, it does not modify the number of activated immune cells. In lung tissue, $\mathrm{IL}-4^{+}$cells were increased in the SC group. In the supernatants of the macerated lungs, the level of this cytokine in all the sensitised groups (SC, PTREAT and CTREAT) remained similar to that of the NC group. Probably the regulation observed in the CTREAT group is due to the secretion of IL-10 at $7 \mathrm{dPS}$.

At the mucosal site, S-IgA is the main antibody produced and plays an important role in protecting the host against antigens that constantly prime the epithelial mucosa surface ${ }^{(35)}$. It is known that defects in the synthesis of the polymeric Ig receptor from mucosal epithelial cells are associated with Th2 inflammation in the airways ${ }^{(35,36)}$.

Previous studies have shown that PFM, similar to that used in the present study, increased the total S-IgA level in the gut of normal animals ${ }^{(37)}$. Taking this into account, we evaluated whether PFM administration had the same effect in the lung mucosa of sensitised animals. PFM increased not only the
IgA-producing cells, but also the secretion of IgA in the BALF of the CTREAT group at 7 and $15 \mathrm{dPS}$. In this sense, the increase observed in the level of IFN- $\gamma$ could favour the release of S-IgA, which is in agreement with a report indicating that IFN- $\gamma$ is involved in the synthesis of polymeric Ig receptor $^{(38)}$.

The present results suggest that the regulatory effect of PFM on the immune response in an OVA-sensitised mice model is mainly due to the high levels of IL-10 and IFN- $\gamma$, showing a Th1-driven immune response. In addition to the reduction in the specific IgE level, IFN- $\gamma$ could promote an increase in the IgG2a level in serum and in total S-IgA level in the lungs. Moreover, another function of IFN- $\gamma$ is the induction of $\mathrm{T}_{\text {reg }}$ cells that could be involved in the regulatory effect observed for $\mathrm{PFM}^{(31)}$. Other authors have demonstrated that the administration of Lactobacillus reuteri increased the number of $\mathrm{T}_{\text {reg }}$ cells in the spleen of asthma-induced mice $^{(39)}$. Feleszko et $a l .{ }^{(40)}$ established in a murine model of asthma that probiotic bacteria-induced $\mathrm{T}_{\text {reg }}$ cells inhibit subsequent allergic sensitisation and airway disease. According to these findings, we evaluated the expression of $\mathrm{T}_{\text {reg }}$ cells in the lungs. Interestingly, in our experimental model of allergy, we found that PFM does not affect the expression of $\mathrm{CD} 4{ }^{+} \mathrm{CD} 25^{+} \mathrm{Foxp}^{+} \mathrm{T}_{\text {reg }}$ cells in the lungs, reinforcing our hypothesis that PFM favours a Th1 balance associated with IFN- $\gamma$ production. We also demonstrated that PFM favours the improvement of lung tissues with an increase in the alveolar space (Fig. 7).

The most important fact demonstrated in the present study is that PFM intake strongly favours the $\operatorname{IgG}$ response to the antigen, probably by the regulation of B-cell clones to produce specific IgG instead of IgE through the activation of IFN- $\gamma$.

\section{Supplementary material}

To view supplementary material for this article, please visit http://dx.doi.org/10.1017/S0007114515001981

\section{Acknowledgements}

The authors thank Azul Zorzoli, Biochemist, for her assistance with the data analysis of $\mathrm{T}_{\text {reg }}$ cells.

The present study was financially supported by Consejo Nacional de Investigaciones Científicas y Técnicas grant, CONICET PIP 0652, CIUNT 26/D442 (Tucumán University) and by DANONE, Argentina.

The authors' contributions are as follows: E. M. M. V. and C. M. G. carried out the microbiological work, animal studies and immunological determination; G. P. and M. E. B. B. conceived the study; C. M. G. and G. P. designed the experiments; E. C. and R. W. provided PFM and participated in the discussion; E. M. M. V. and C. M. performed the statistical analysis and prepared the figures; E. M. M. V., C. M. G. and G. P. wrote the draft of the manuscript. All authors read and approved the final version of the manuscript.

The authors declare that they have no conflicts of interest. 


\section{References}

1. Becker Y (2006) Respiratory syncytial virus (RSV) evades the human adaptive immune system by skewing the Th1/Th2 cytokine balance toward increased levels of Th2 cytokines and IgE, markers of allergy - a review. Virus Genes 33, 235-252.

2. Brown EM, Arrieta MC \& Finlay BB (2013) A fresh look at the hygiene hypothesis: how intestinal microbial exposure drives immune effector responses in atopic disease. Semin Immunol 25, 378-387.

3. Romagnani S (2004) The increased prevalence of allergy and the hygiene hypothesis: missing immune deviation, reduced immune suppression, or both? Immunology 112, 352-363.

4. Bjorksten B (2009) Disease outcomes as a consequence of environmental influences on the development of the immune system. Curr Opin Allergy Clin Immunol 9, 185-189.

5. Penders J, Stobberingh EE, van den Brandt PA, et al. (2007) The role of the intestinal microbiota in the development of atopic disorders. Allergy 62, 1223-1236.

6. FAO/WHO (2001) Evaluation of health and nutritional properties of powder milk and live lactic acid bacteria. Food and Agriculture Organization of the United Nations and World Health Organization Expert Consultation Report. ftp://ftp.fao.org/docrep/fao/009/a0512e/a0512e00.pdf

7. de LeBlanc Ade M, Castillo NA \& Perdigon G (2010) Antiinfective mechanisms induced by a probiotic Lactobacillus strain against Salmonella enterica serovar Typhimurium infection. Int J Food Microbiol 138, 223-231.

8. Guo C \& Zhang L (2010) Cholesterol-lowering effects of probiotics - a review. Wei Sheng Wu Xue Bao 50, 1590-1599.

9. Pan DD, Zeng XQ \& Yan YT (2011) Characterisation of Lactobacillus fermentum SM-7 isolated from koumiss, a potential probiotic bacterium with cholesterol-lowering effects. J Sci Food Agric 91, 512-518.

10. Galdeano CM \& Perdigon G (2006) The probiotic bacterium Lactobacillus casei induces activation of the gut mucosal immune system through innate immunity. Clin Vaccine Immunol 13, 219-226.

11. Ouwehand AC (2007) Antiallergic effects of probiotics. J Nutr 137, 794S-797S.

12. Ishida Y, Bandou I, Kanzato H, et al. (2003) Decrease in ovalbumin specific IgE of mice serum after oral uptake of lactic acid bacteria. Biosci Biotechnol Biochem 67, 951-957.

13. Ohno H, Tsunemine S, Isa Y, et al. (2005) Oral administration of Bifidobacterium bifidum G9-1 suppresses total and antigen specific immunoglobulin $\mathrm{E}$ production in mice. Biol Pharm Bull 28, 1462-1466.

14. Morita H, He F, Kawase M, et al. (2006) Preliminary human study for possible alteration of serum immunoglobulin $\mathrm{E}$ production in perennial allergic rhinitis with fermented milk prepared with Lactobacillus gasseri TMC0356. Microbiol Immunol 50, 701-706.

15. Blumer N, Sel S, Virna S, et al. (2007) Perinatal maternal application of Lactobacillus rhamnosus GG suppresses allergic airway inflammation in mouse offspring. Clin Exp Allergy 37, 348-357.

16. Kim Y, Lee MY, Kim OS, et al. (2014) Acute oral toxicity of Insampaedok-san, a traditional herbal formula, in rats and its protective effects against ovalbumin-induced asthma via anti-inflammatory and antioxidant properties. BMC Complement Altern Med 14, 365.

17. Wu Y, Fu H, Yang H, et al. (2014) Smooth muscle progenitor cells involved in the development of airway remodeling in a murine model of asthma. Asian Pac J Allergy Immunol 32, 203-210.
18. Maldonado Galdeano C, Novotny Nunez I, de Moreno de LeBlanc A, et al. (2011) Impact of a probiotic fermented milk in the gut ecosystem and in the systemic immunity using a non-severe protein-energy-malnutrition model in mice. BMC Gastroenterol 11, 64.

19. Perdigón G, Maldonado Galdeano C, Valdez JC, et al. (2002) Interaction of lactic acid bacteria with the gut immune system. Eur J Clin Nutr 56, Suppl. 4, S21-S26.

20. de Moreno de LeBlanc A, Dogi CA, Galdeano CM, et al. (2008) Effect of the administration of a fermented milk containing Lactobacillus casei DN-114001 on intestinal microbiota and gut associated immune cells of nursing mice and after weaning until immune maturity. $B M C$ Immunol 9, 27.

21. Enander I, Ahlstedt S, Nygren H, et al. (1983) Sensitizing ability of derivatives of picryl chloride after exposure of mice on the skin and in the lung. Int Arch Allergy Appl Immunol 72, 59-66.

22. Yu J, Jang SO, Kim BJ, et al. (2010) The effects of Lactobacillus rhamnosus on the prevention of asthma in a murine model. Allergy Asthma Immunol Res 2, 199-205.

23. MacSharry J, O'Mahony C, Shalaby KH, et al. (2012) Immunomodulatory effects of feeding with Bifidobacterium longum on allergen-induced lung inflammation in the mouse. Pulm Pharmacol Ther 25, 325-334.

24. Forsythe P, Inman MD \& Bienenstock J (2007) Oral treatment with live Lactobacillus reuteri inhibits the allergic airway response in mice. Am J Respir Crit Care Med 175, 561-569.

25. Meijerink M, Wells JM, Taverne N, et al. (2012) Immunomodulatory effects of potential probiotics in a mouse peanut sensitization model. FEMS Immunol Med Microbiol 65, 488-496.

26. de Moreno de LeBlanc A, Chaves S, Carmuega E, et al. (2008) Effect of long-term continuous consumption of fermented milk containing probiotic bacteria on mucosal immunity and the activity of peritoneal macrophages. Immunobiology 213, 97-108.

27. Kalliomaki M, Salminen S, Arvilommi H, et al. (2001) Probiotics in primary prevention of atopic disease: a randomised placebo-controlled trial. Lancet 357, 1076-1079.

28. Kalliomaki M, Salminen S, Poussa T, et al. (2003) Probiotics and prevention of atopic disease: 4-year follow-up of a randomised placebo-controlled trial. Lancet 361, 1869-1871.

29. Galdeano CM, de Moreno de LeBlanc A, Vinderola G, et al. (2007) Proposed model: mechanisms of immunomodulation induced by probiotic bacteria. Clin Vaccine Immunol $\mathbf{1 4}$, 485-492.

30. Hattori K, Nishikawa M, Watcharanurak K, et al. (2010) Sustained exogenous expression of therapeutic levels of IFN-gamma ameliorates atopic dermatitis in $\mathrm{NC} / \mathrm{Nga}$ mice via Th1 polarization. J Immunol 184, 2729-2735.

31. Kelchtermans H, Billiau A \& Matthys P (2008) How interferon-gamma keeps autoimmune diseases in check. Trends Immunol 29, 479-486.

32. Perdigón G, Maldonado Galdeano C, Valdez JC, et al. (2002) Interaction of lactic acid bacteria with the gut Immune system. Eur J Clin Nutr 56, Suppl. 4, S21-S26.

33. O'Garra A \& Vieira P (2007) T(H)1 cells control themselves by producing interleukin-10. Nat Rev Immunol 7, 425-428.

34. Maldonado Galdeano C, Lemme-Dumit JM, Thieblemont N, et al. (2015) Stimulation of innate immune cells induced by probiotics: participation of Toll-like receptors. J Clin Cell Immunol 6, 283.

35. Hupin C, Rombaux P, Bowen H, et al. (2013) Downregulation of polymeric immunoglobulin receptor and secretory 
IgA antibodies in eosinophilic upper airway diseases. Allergy 68, 1589-1597.

36. Asano M \& Komiyama K (2011) Polymeric immunoglobulin receptor. J Oral Sci 53, 147-156.

37. Galdeano CM, de Leblanc Ade M, Carmuega E, et al. (2009) Mechanisms involved in the immunostimulation by probiotic fermented milk. J Dairy Res 76, 446-454.

38. Amin PB, Diebel LN \& Liberati DM (2007) T-cell cytokines affect mucosal immunoglobulin A transport. Am J Surg 194, 128-133.
39. Karimi K, Inman MD, Bienenstock J, et al. (2009) Lactobacillus reuteri-induced regulatory $\mathrm{T}$ cells protect against an allergic airway response in mice. Am J Respir Crit Care Med 179, 186-193.

40. Feleszko W, Jaworska J, Rha RD, et al. (2007) Probioticinduced suppression of allergic sensitization and airway inflammation is associated with an increase of $\mathrm{T}$ regulatory-dependent mechanisms in a murine model of asthma. Clin Exp Allergy 37, 498-505. 